\title{
Lower Drug Cost of Successfully Treating Patients with Type 2 Diabetes to Targets with Once-Weekly Semaglutide versus Once-weekly Dulaglutide in Japan: A Short-Term Cost-Effectiveness Analysis
}

\author{
Ataru Igarashi · Barnaby Hunt (D) - Lars Wilkinson · Jakob Langer • \\ Richard F. Pollock
}

Received: July 22, 2020 / Published online: September 1, 2020

(c) The Author(s) 2020

\section{ABSTRACT}

Introduction: In the head-to-head trial (SUSTAIN 7), the novel, injectable, once-weekly GLP-1 analogue semaglutide showed superiority in both glycemic outcomes and body weight reduction, compared with once-weekly dulaglutide in the treatment of type 2 diabetes (T2D). However, no economic evaluation using these data has yet been conducted in the Japanese setting. The objective of this analysis was to assess the short-term cost-effectiveness in Japan of once-weekly semaglutide $0.5 \mathrm{mg}$ (the

Digital Features To view digital features for this article go to https://doi.org/10.6084/m9.figshare.12794195.

A. Igarashi

Unit of Public Health and Preventive Medicine,

Yokohama City University School of Medicine,

Yokohama, Japan

A. Igarashi

Department of Health Economics and Outcomes

Research, Graduate School of Pharmaceutical

Sciences, The University of Tokyo, Tokyo, Japan

B. Hunt $(\bowtie) \cdot$ R. F. Pollock

Ossian Health Economics and Communications

$\mathrm{GmbH}$, Basel, Switzerland

e-mail: hunt@ossianconsulting.com

L. Wilkinson

Novo Nordisk A/S, Søborg, Denmark

J. Langer

Novo Nordisk Pharma Ltd., Tokyo, Japan approved maintenance dose in Japan) compared with once-weekly dulaglutide $0.75 \mathrm{mg}$ (the only licensed dose in Japan) over a 1-year period using Japanese cost data.

Methods: Responder endpoints were obtained from the SUSTAIN 7 trial to assess the cost of successfully treating patients to these targets ("cost of control"). Responder endpoint definitions consisted of single, dual, and triple composite endpoints related to glycemic control, body weight, and hypoglycemia outcomes. The cost of treatment was accounted from a healthcare payer perspective, capturing drug costs only. Results: Treatment with once-weekly semaglutide $0.5 \mathrm{mg}$ was associated with a lower cost and a lower cost per patient treated to target for all endpoints, compared with once-weekly dulaglutide $0.75 \mathrm{mg}$. For each JPY 1 spent on bringing patients to target with once-weekly semaglutide $0.5 \mathrm{mg}$, JPY 1.58, JPY 1.44, JPY 1.60, JPY 2.10, and JPY 2.33 would need to be spent on once-weekly dulaglutide $0.75 \mathrm{mg}$ to achieve an equivalent outcome for endpoints of HbA1c $\leq 6.5 \%$, HbA1c $<7.0 \%$, HbA1c $<7.0 \%$ without hypoglycemia, and no weight gain, weight loss $\geq 5 \%$, and $\geq 1.0 \%$ HbA1c reduction and $\geq 3.0 \%$ weight loss, respectively.

Conclusions: These findings suggest that onceweekly semaglutide is a cost-effective treatment option compared with once-weekly dulaglutide for patients with T2D in Japan. In the future, this finding should be extrapolated to traditional long-term cost-effectiveness analysis, 
using common outcomes such as quality-adjusted life years.

Keywords: Cost-benefit; Costs and cost analysis; Diabetes mellitus; Glucagon-like peptides; Japan; Semaglutide; Type 2

\section{Key Summary Points}

Why carry out this study?

Type 2 diabetes (T2D) poses a significant clinical and economic burden in Japan, and use of therapies that are both effective and cost-effective will improve outcomes for patients and control costs for healthcare payers.

The aim of the present analysis was to evaluate the absolute and relative costs of bringing Japanese patients with T2D to various clinically relevant treatment targets covering bodyweight, hypoglycemia incidence, and glycemic control recommended by the Japanese Diabetes Society based on the findings of the SUSTAIN 7 randomized controlled trial.

The approach of calculating the cost associated with bringing patients to a series of pre-specified composite and single endpoints confers the benefit of balancing costs and effects in a simple, transparent and clinically-relevant manner that is well-suited to short-term evaluations of cost-effectiveness.

\section{What was learned from the study?}

Treatment with injectable once-weekly semaglutide $0.5 \mathrm{mg}$ was associated with a lower cost and a lower cost per patient treated to target for all endpoints, compared with once-weekly dulaglutide $0.75 \mathrm{mg}$.

Once-weekly semaglutide is likely to be a cost-effective treatment option compared with once-weekly dulaglutide for patients with T2D in Japan.

\section{INTRODUCTION}

The prevalence of diabetes among adults in Japan was estimated by the International Diabetes Federation to be 7.4 million, representing $5.6 \%$ of the adult population, with a further estimated 12.1 million people with impaired glucose tolerance [1]. With average annual diabetes-related expenditure (including costs of antidiabetic medications, costs of treating complications, and screening and management programs) of USD 3179 per patient, Japan ranking fifth in the world for absolute expenditure on diabetes, and the prevalence expected to increase to $6.6 \%$ by 2045 , there is continually increasing pressure to optimize healthcare expenditure on diabetes therapies [1,2].

Given the high economic burden of treating diabetes complications and the negative effects on patient quality of life, reducing the incidence of complications is beneficial from both the healthcare payer and patient perspectives. Data from large-scale studies, such as the Funagata Diabetes Study, the Kumamoto Study, and the Japan Diabetes Complications Study, have shown that improving glycemic control reduces the risk of micro- and macro-vascular complications in patients with diabetes [3-5]. Based on evidence from studies such as the United Kingdom Prospective Diabetes Study, the Funagata Diabetes Study, and the Kumamoto Study, the Japanese Diabetes Society (JDS) recommends a glycated hemoglobin (HbA1c) target of $<7 \%$ in most patients, with the objective of reducing the risk of complication incidence $[3,6]$. In addition to maintaining tight glycemic control, the JDS guidelines also recommend reducing bodyweight (particularly in overweight or obese patients, defined as body mass index $23.0-24.9 \mathrm{~kg} / \mathrm{m}^{2}$ and $\geq 25 \mathrm{~kg} / \mathrm{m}^{2}$, respectively), minimizing the risk of hypoglycemia, and controlling blood pressure and serum lipid levels [6].

The GLP-1 receptor agonists (RAs) are highly efficacious, and generally also associated with reductions in bodyweight and low risk of hypoglycemia. The JDS treatment guidelines recommend GLP-1 RAs as one option for treatment in patients inadequately controlled with 
diet and exercise and/or metformin alone. Once-weekly semaglutide is a novel, injectable GLP-1 analogue, the efficacy of which has been shown in the Semaglutide Unabated Sustainability in Treatment of Type 2 Diabetes (SUSTAIN) trial program that comprises ten phase 3 global clinical trials, including one cardiovascular outcomes trial and two Japanese local trials conducted exclusively in Japan: one comparing once-weekly semaglutide with sitagliptin and one comparing semaglutide with oral anti-diabetic medications [7, 8]. In total, the SUSTAIN program has enrolled more than 9000 adults with T2D.

As concerns around the rapidly ageing population of Japan grow, economic evaluation of new technologies is playing an increasingly important role in decisions around reimbursed therapies. Submission of health-economic data has been optional since 1992, but a 3-year pilot health technology assessment program was initiated in 2016 [9, 10]. Following this, a set of requirements for pharmacoeconomic evaluation were approved in 2019, giving a formal framework for evaluating the cost-effectiveness of new healthcare interventions coming to market in Japan $[11,12]$.

The aim of the present analysis was to evaluate the absolute and relative costs of bringing Japanese patients with T2D to various clinically relevant treatment targets, covering bodyweight, hypoglycemia incidence, and glycemic control, recommended by the JDS with injectable once-weekly semaglutide $0.5 \mathrm{mg}$ (the approved maintenance dose in Japan) compared with once-weekly dulaglutide $0.75 \mathrm{mg}$ (the only licensed dose in Japan), based on the findings of the SUSTAIN 7 randomized controlled trial (RCT) and an indirect analysis conducted in Japanese patients with T2D [13]. A cost of control modeling approach was adopted based on previously published economic analyses of once-weekly semaglutide in the USA and Spain [14-16]. The approach of calculating the cost associated with bringing patients to a series of pre-specified composite and single endpoints confers the benefit of balancing costs and effects in a simple, transparent, and clinically-relevant manner that is well-suited to short-term evaluations of costeffectiveness.

\section{METHODS}

\section{Clinical Data}

The clinical data driving the analysis were based on the SUSTAIN 7 RCT, a 40-week randomized, open-label, active-controlled, parallel group, multicenter, multinational, four-armed trial comparing two dose levels of once-weekly semaglutide $(0.5 \mathrm{mg}$ and $1.0 \mathrm{mg})$ versus two dose levels of once-weekly dulaglutide $(0.75 \mathrm{mg}$ and $1.5 \mathrm{mg}$ ) in subjects diagnosed with T2D inadequately controlled with metformin alone [13]. Of 1663 subjects evaluated for eligibility, 1201 patients were randomly assigned $1: 1: 1: 1$ to the four trial arms, with 1199 patients ultimately receiving the study drug, 1129 patients completing the trial, and 1038 completing treatment. The two principal comparisons were of once-weekly semaglutide $0.5 \mathrm{mg}$ versus dulaglutide $0.75 \mathrm{mg}$ and once-weekly semaglutide $1.0 \mathrm{mg}$ versus dulaglutide $1.5 \mathrm{mg}$. In Japan, semaglutide $0.5 \mathrm{mg}$ is the approved maintenance dose and dulaglutide $0.75 \mathrm{mg}$ is the only licensed dose. Therefore, the present cost of control analysis compared only semaglutide $0.5 \mathrm{mg}$ with dulaglutide $0.75 \mathrm{mg}$.

The primary endpoint was the change from baseline to week 40 in $\mathrm{HbA1c}$, with the estimated treatment difference from a mixed model for repeated measurements analysis using data for all randomized patients exposed to at least one dose of trial product (full analysis set) obtained while on treatment and before onset of rescue medication. The confirmatory secondary endpoint was change from baseline to week 40 in bodyweight $(\mathrm{kg})$. Once-weekly semaglutide $0.5 \mathrm{mg}$ was superior to dulaglutide $0.75 \mathrm{mg}$ in terms of change from baseline in HbA1c, with changes of $-1.51 \%$ with semaglutide $0.5 \mathrm{mg}$ compared with $-1.11 \%$ with dulaglutide $0.75 \mathrm{mg}$, giving an estimated treatment difference of $-0.40 \%$ (95\% confidence interval -0.55 to $-0.25 \%$ ). Similarly, from a mean baseline bodyweight of $95.24 \mathrm{~kg}$ across the groups, the estimated change from 
baseline in body weight at week 40 was $-4.56 \mathrm{~kg}$ with semaglutide $0.5 \mathrm{mg}$ compared with $-2.30 \mathrm{~kg}$ with dulaglutide $0.75 \mathrm{mg}$, yielding an estimated treatment difference of $-2.26 \mathrm{~kg}$ (95\% confidence interval -3.02 to $-1.51 \mathrm{~kg})$.

As SUSTAIN 7 did not include Japanese patients with T2D, a network meta-analysis (NMA) has previously been conducted to compare the efficacy of once-weekly semaglutide and dulaglutide in Japanese patients with T2D [17]. The findings from the NMA showed significant improvements with once-weekly semaglutide versus dulaglutide in terms of HbA1c, body weight and systolic blood pressure, thereby corroborating the SUSTAIN 7 results. The goal attainment of $\mathrm{HbA} 1 \mathrm{c}<7 \%$ from the NMA was used in an additional analysis to assess the cost of control in Japanese patients for once-weekly semaglutide versus dulaglutide.

\section{Model}

A cost of control model was developed in Microsoft Excel (Microsoft, Redmond, WA, USA) to evaluate the numbers needed to treat (NNT), and the absolute and relative costs of bringing a single patient to each of the prespecified composite and single endpoints in SUSTAIN 7, covering glycemic targets, bodyweight, and hypoglycemia outcomes: HbA1c $6.5 \%$ or lower, HbA1c lower than $7.0 \%$, HbA1c lower than $7.0 \%$ without hypoglycemia or weight gain, HbA1c reduction $1.0 \%$ or greater with $3.0 \%$ or larger reduction in bodyweight, and $5.0 \%$ or larger reduction in bodyweight (Table 1). An additional analysis of HbA1c lower than $7.0 \%$ was prepared based on the NMA (Table 1).

\section{Cost Data and Time Horizon}

The analysis was conducted from the perspective of a national healthcare payer in Japan over a 1-year time horizon, capturing costs borne by the healthcare payer expressed in 2020 Japanese yen (JPY). The only costs included in the analysis were drug costs, with costs of all other aspects of treatment assumed to be the same in both arms and therefore excluded. Drug prices were provided by Novo Nordisk Pharma, Tokyo, Japan, and reflected costs to healthcare payers (Table 2). Given the identical administration schedule, adherence to both dulaglutide and once-weekly semaglutide was assumed to be the equivalent, and was conservatively (from the payer perspective) assumed to be $100 \%$.

\section{Effectiveness and Cost-Effectiveness Calculations}

The NNT for one patient to reach each target was calculated in absolute terms for each endpoint for semaglutide $0.5 \mathrm{mg}$ and dulaglutide $0.75 \mathrm{mg}$ (i.e., the reciprocal of the proportion of patients reaching each target). Annual treatment costs with semaglutide $0.5 \mathrm{mg}$ and dulaglutide $0.75 \mathrm{mg}$ were calculated based on the pharmacy costs. Cost of control calculations were conducted by dividing the annual treatment cost by the proportion of patients reaching each target to give the absolute cost of control. The approach was conservative, potentially marginally overestimating cost of control, capturing a full year of treatment costs despite control being achieved after 40 weeks in the SUSTAIN 7 RCT. Relative cost of control was then calculated by dividing the cost of control with dulaglutide $0.75 \mathrm{mg}$ by the cost of control with semaglutide $0.5 \mathrm{mg}$. This gives the spending required with dulaglutide $0.75 \mathrm{mg}$ to bring one patient to target for every JPY 1 spent on bringing patients to target with once-weekly semaglutide $0.5 \mathrm{mg}$. An example calculation for the endpoint of HbA1c lower than $7.0 \%$ without hypoglycemia or weight gain is shown in Table 3.

\section{Sensitivity Analyses}

One-way sensitivity analyses were conducted around the base case varying the proportion of patients reaching each target by an approximation of the standard error (SE) derived using the formula where $n$ represents the number of patients in each arm of the SUSTAIN 7 RCT and 
Table 1 Proportion of patients reaching target with once-weekly semaglutide $0.5 \mathrm{mg}$ and dulaglutide $0.75 \mathrm{mg}$, both in combination with metformin

Once-weekly semaglutide $0.5 \mathrm{mg}$ Dulaglutide $0.75 \mathrm{mg}$

\begin{tabular}{lll}
\hline SUSTAIN 7 (40 weeks) & \\
HbAlc $\leq 6.5 \%$ & $49 \%$ & $34 \%$ \\
HbAlc $<7.0 \%$ & $68 \%$ & $52 \%$ \\
HbAlc $<7.0 \%$ without hypoglycemia, and no weight gain & $64 \%$ & $44 \%$ \\
Weight loss $\geq 5 \%$ & $44 \%$ & $23 \%$ \\
$\geq 1.0 \%$ HbAlc reduction and $\geq 3.0 \%$ weight loss & $53 \%$ & $25 \%$ \\
NMA in Japanese patients & & \\
HbAlc $<7.0 \%$ & $78 \%$ & $64 \%$ \\
\hline
\end{tabular}

HbAlc glycated hemoglobin, NMA network meta-analysis

Table 2 Drug costs in Japan in the base case analysis

\begin{tabular}{lll}
\hline Glucagon-like peptide $\mathbf{1}$ treatment & Pen contents & Pen price (JPY) \\
\hline Once-weekly semaglutide $0.5 \mathrm{mg}$ & $0.5 \mathrm{mg}$ & 3094 \\
Dulaglutide $0.75 \mathrm{mg}$ & $0.75 \mathrm{mg}$ & 3396 \\
\hline
\end{tabular}

JPY 2020 Japanese Yen

$\mathrm{p}$ represents the proportion of patients reaching target: $\sqrt{\frac{1}{n} p(1-p)}$.

\section{Compliance with Ethics Guidelines}

This article is based on previously conducted studies and does not contain any studies with human participants or animals performed by any of the authors.

\section{RESULTS}

\section{Annual Treatment Costs}

The annual drug cost with semaglutide $0.5 \mathrm{mg}$ was JPY 161,441 compared with JPY 177,198 with once-weekly dulaglutide $0.75 \mathrm{mg}$, based on the assumption of $100 \%$ adherence to both medications. Over a 1-year time horizon, semaglutide $0.5 \mathrm{mg}$ was $9 \%$ less costly than dulaglutide $0.75 \mathrm{mg}$.

\section{Numbers Needed to Treat}

The proportions of patients reaching each target were higher with once-weekly semaglutide $0.5 \mathrm{mg}$ for all endpoints compared with dulaglutide $0.75 \mathrm{mg}$ (Fig. 1). Differences were largest for the endpoints of $\geq 1.0 \% \mathrm{HbA} 1 \mathrm{c}$ reduction and $\geq 3.0 \%$ weight loss, and weight loss $\geq 5 \%$. The smallest difference was observed when the NMA was used to inform the number of patients achieving HbA1c $<7.0 \%$.

\section{Cost of Control}

The analysis found that the cost of bringing one patient to target was universally lower with once-weekly semaglutide $0.5 \mathrm{mg}$ relative to dulaglutide $0.75 \mathrm{mg}$. Relative costs of control, 
Table 3 Example cost of control calculation based on the proportion of patients achieving an HbAlc target of $<7.0 \%$ without hypoglycemia and with no weight gain

\begin{tabular}{|c|c|c|c|}
\hline & $\begin{array}{l}\text { Once-weekly } \\
\text { semaglutide } 0.5 \mathrm{mg}\end{array}$ & Dulaglutide $0.75 \mathrm{mg}$ & Interpretation \\
\hline Annual treatment cost (JPY) & 161,441 & 177,198 & \\
\hline Drug cost index & $\begin{array}{l}161,441 / \\
177,198=0.91\end{array}$ & $\begin{array}{l}177,198 / \\
177,198=1.00\end{array}$ & $\begin{array}{l}\text { Treatment with once-weekly } \\
\text { semaglutide } 0.5 \mathrm{mg} \text { is } 9 \% \text { less } \\
\text { expensive than treatment with } \\
\text { dulaglutide } 0.75 \mathrm{mg}\end{array}$ \\
\hline $\begin{array}{l}\text { Drug efficacy (\% of patients } \\
\text { with HbAlc }<7 \% \text {, and } \\
\text { no hypoglycemia or } \\
\text { weight gain) }\end{array}$ & $64 \%$ & $44 \%$ & \\
\hline Drug efficacy index & $64 / 44=1.45$ & $44 / 44=1.00$ & $\begin{array}{l}\text { Once-weekly semaglutide } 0.5 \mathrm{mg} \text { is } 45 \% \\
\text { more effective at bringing patients to } \\
\text { target than dulaglutide } 0.75 \mathrm{mg}\end{array}$ \\
\hline $\begin{array}{l}\text { Cost per patient achieving } \\
\text { control (JPY) }\end{array}$ & $\begin{array}{l}161,441 / \\
\quad 64 \times 100=252,251\end{array}$ & $\begin{array}{l}177,198 / \\
44 \times 100=402,724\end{array}$ & \\
\hline $\begin{array}{l}\text { Amount spent to achieve } \\
\text { target relative to JPY } 1 \\
\text { spent on once-weekly } \\
\text { semaglutide }\end{array}$ & $\begin{array}{l}252,251 / \\
252,251=1.00\end{array}$ & $\begin{array}{l}402,724 / \\
252,251=1.60\end{array}$ & $\begin{array}{l}\text { For every JPY } 1 \text { spent on bringing } \\
\text { patients to target with once-weekly } \\
\text { semaglutide } 0.5 \mathrm{mg} \text {, JPY } 1.60 \text { would } \\
\text { need to be spent on dulaglutide } \\
0.75 \mathrm{mg}\end{array}$ \\
\hline
\end{tabular}

HbA1c glycated hemoglobin, JPY 2020 Japanese Yen

which uses once-weekly semaglutide $0.5 \mathrm{mg}$ as the reference with an index of 100, shows the spending required with dulaglutide $0.75 \mathrm{mg}$ to achieve an equivalent outcome (Fig. 2). For every JPY 1 spent on bringing patients to targets of $\mathrm{HbA} 1 \mathrm{c} \leq 6.5 \%$ and $\mathrm{HbA} 1 \mathrm{c}<7.0 \%$ with onceweekly semaglutide $0.5 \mathrm{mg}$, spending of JPY 1.58 and JPY 1.44, respectively, would need to be spent on dulaglutide $0.75 \mathrm{mg}$ to achieve an equivalent outcome. For the composite endpoint of $\mathrm{HbA} 1 \mathrm{c}<7.0 \%$ without hypoglycemia, and no weight gain, spending of JPY 1.60 was required with dulaglutide for every JPY 1 spent of semaglutide $0.5 \mathrm{mg}$. When the treatment target of weight loss $\geq 5 \%$ was considered, for each JPY 1 spent on semaglutide $0.5 \mathrm{mg}$, spending of JPY 2.10 was required with dulaglutide $0.75 \mathrm{mg}$ to bring one patient to target. For each JPY 1 spent on semaglutide $0.5 \mathrm{mg}$ to bring a patient to the target of $\geq 1.0 \%$ HbA1c reduction and $\geq 3.0 \%$ weight loss, spending of JPY 2.33 was required with dulaglutide to achieve an equivalent clinical outcome.

When the NMA was used to inform the proportion of patients achieving the target of HbA1c $<7.0 \%$, differences between the treatment arms were smaller, but spending to achieve an equivalent clinical outcome remained lower with semaglutide $0.5 \mathrm{mg}$ than with dulaglutide $0.75 \mathrm{mg}$. For each JPY 1 spent on semaglutide, spending of JPY 1.34 was required with dulaglutide to achieve an equivalent clinical outcome. 


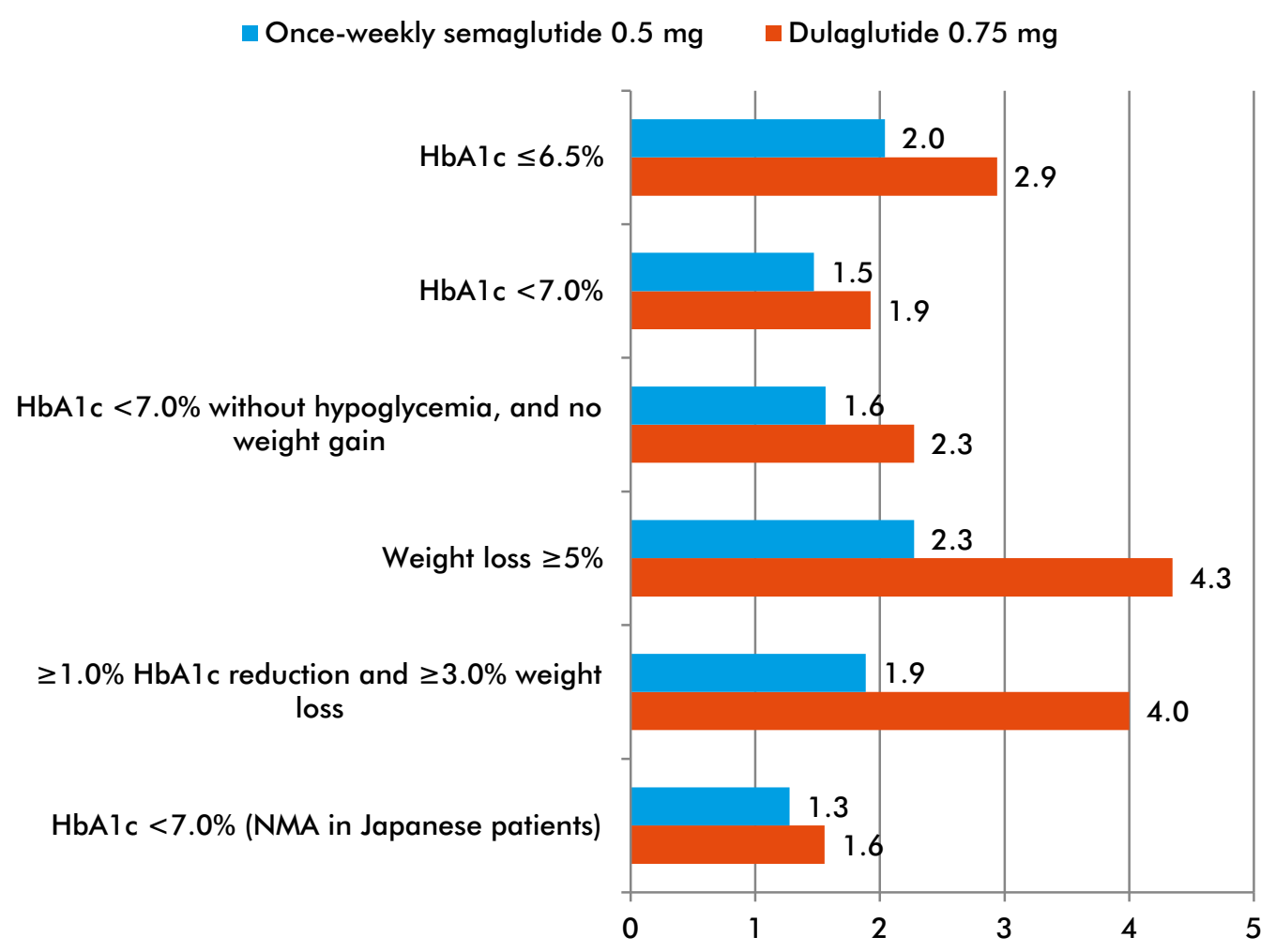

Fig. 1 Numbers needed to treat to bring one patient to target with once-weekly semaglutide 0.5 and dulaglutide $0.75 \mathrm{mg}$. $H b A 1 c$ glycated hemoglobin, NMA network meta-analysis

\section{Sensitivity Analyses}

One-way sensitivity analyses showed that, when the proportion of patients reaching target was increased by one SE with once-weekly semaglutide $0.5 \mathrm{mg}$ and dulaglutide $0.75 \mathrm{mg}$, differences between the treatment arms were reduced compared with the base case analysis (Table 4). However, the conclusions were unchanged with the cost of bringing one patient to target remaining lower with onceweekly semaglutide $0.5 \mathrm{mg}$ relative to dulaglutide $0.75 \mathrm{mg}$ for all endpoints. When the proportion of patients reaching target was decreased by one SE with once-weekly semaglutide $0.5 \mathrm{mg}$ and dulaglutide $0.75 \mathrm{mg}$, differences in the relative cost of control were larger than in the base case. The largest difference was seen for the endpoint $\geq 1.0 \% \mathrm{HbA} 1 \mathrm{c}$ reduction and $\geq 3.0 \%$ weight loss, where for each JPY 1 spent on semaglutide, spending of JPY 2.45 was required with dulaglutide to achieve an equivalent clinical outcome. The model outputs were relatively insensitive to variations in key clinical input parameters and the conclusions based on the analysis were therefore considered to be robust.

\section{DISCUSSION}

The present study used the findings of the SUSTAIN 7 RCT of 1201 patients with T2D to compare the cost of bringing a patient to each of five defined clinical targets in the trial with injectable once-weekly semaglutide $0.5 \mathrm{mg}$ relative to once-weekly dulaglutide $0.75 \mathrm{mg}$. The RCT reported that once-weekly semaglutide was superior to the dulaglutide in terms of the primary and secondary endpoints of HbA1c reduction and bodyweight reduction over 40 weeks. The modeling analysis showed that these benefits would universally result in cost savings with once-weekly semaglutide $0.5 \mathrm{mg}$ relative to dulaglutide $0.75 \mathrm{mg}$ when bringing 


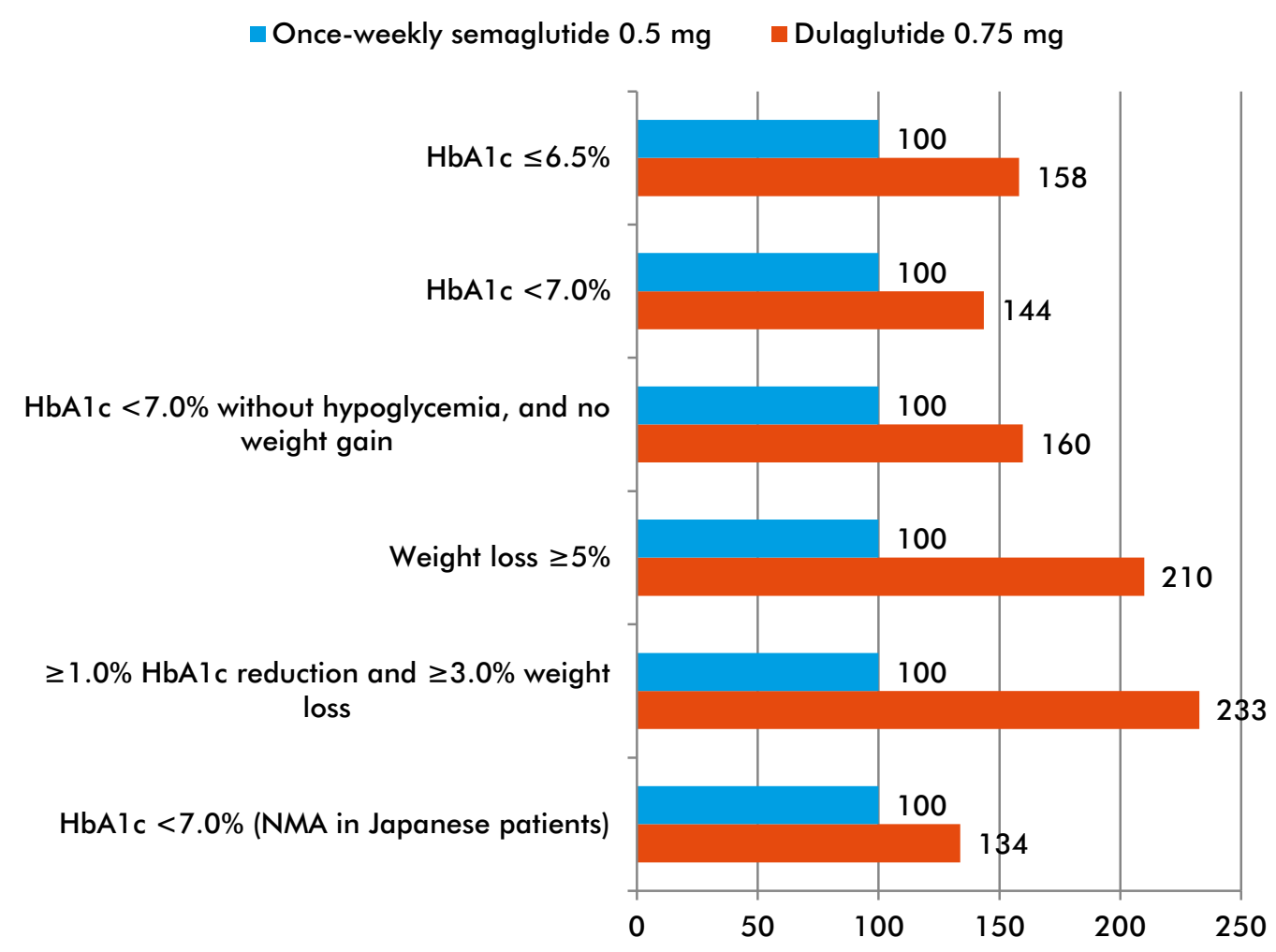

Fig. 2 Relative cost of control with dulaglutide $0.75 \mathrm{mg}$ versus once-weekly semaglutide $0.5 \mathrm{mg}($ index $=100)$. $H b A 1 c$ glycated hemoglobin, NMA network meta-analysis

patients to a series of clinically relevant targets investigated in the SUSTAIN 7 RCT. Using an NMA conducted using exclusively Japanese data to inform the proportion of patients achieving an $\mathrm{HbA} 1 \mathrm{c}<7.0 \%$ confirmed that the results were robust. Semaglutide is less costly and more effective than dulaglutide; however, this cost per responder analysis was carried out to quantify the differences in terms of cost of successful treatment in a way that is relevant to clinical decision-makers and healthcare payers.

The health technology assessment framework established for Japan in 2019 recommends cost-utility analysis, with calculation of incremental cost-effectiveness ratios based on direct costs and quality-adjusted life expectancy [12]. However, the use of quality-adjusted life expectancy as an outcome measure in Japan remains controversial, with some members of the committee that developed the cost-effectiveness evaluation guidelines opposed to their use [10]. The methods employed in the present analysis could be considered a mid-point between budget impact analysis (considering only costs) and cost-utility analysis (considering cost-utility within a well-established, typically quality-adjusted life year-based willingness-to-pay context). By modeling the cost of achieving various clinically relevant endpoints, the analysis presents cost of control outcomes that should be intuitive to practicing diabetologists. The present analysis is intended to complement, rather than replace, the use of conventional modeling assessing the cost per quality-adjusted life year gained. The aim is to present useful data over a short time horizon in order to aid healthcare decision-making and optimizing the use of finite healthcare resources in Japan.

The analysis is likely to be most useful as a comparative tool for decision-makers interested in a short-term time horizon; longer time horizons or stakeholders that require comparisons to be drawn with other antihyperglycemic agents would be better addressed by an analysis in which the cost per quality-adjusted life year 
Table 4 Relative cost of control with dulaglutide $0.75 \mathrm{mg}$ versus once-weekly semaglutide $0.5 \mathrm{mg}$ (index $=100$ ) in the oneway sensitivity analyses

\begin{tabular}{|c|c|c|c|c|}
\hline \multirow[t]{2}{*}{ Endpoint } & \multicolumn{2}{|c|}{$\begin{array}{l}\text { Proportion reaching target increased } \\
\text { by1 SE compared with the base case }\end{array}$} & \multicolumn{2}{|c|}{$\begin{array}{l}\text { Proportion reaching target reduced } \\
\text { byl SE compared with the base case }\end{array}$} \\
\hline & $\begin{array}{l}\text { Once-weekly } \\
\text { semaglutide } 0.5 \mathrm{mg}\end{array}$ & $\begin{array}{l}\text { Dulaglutide } \\
0.75 \mathrm{mg}\end{array}$ & $\begin{array}{l}\text { Once-weekly } \\
\text { semaglutide } 0.5 \mathrm{mg}\end{array}$ & $\begin{array}{l}\text { Dulaglutide } \\
0.75 \mathrm{mg}\end{array}$ \\
\hline \multicolumn{5}{|l|}{ SUSTAIN 7} \\
\hline $\mathrm{HbAlc} \leq 6.5 \%$ & 100 & 155 & 100 & 162 \\
\hline $\mathrm{HbAlc}<7.0 \%$ & 100 & 141 & 100 & 146 \\
\hline $\begin{array}{l}\mathrm{HbAlc}<7.0 \% \text { without hypoglycemia, } \\
\text { and no weight gain }\end{array}$ & 100 & 156 & 100 & 163 \\
\hline Weight loss $\geq 5 \%$ & 100 & 202 & 100 & 220 \\
\hline $\begin{array}{l}\geq 1.0 \% \mathrm{HbAlc} \text { reduction } \\
\text { and } \geq 3.0 \% \text { weight loss }\end{array}$ & 100 & 223 & 100 & 245 \\
\hline \multicolumn{5}{|l|}{ NMA in Japanese patients } \\
\hline $\begin{array}{l}\text { HbAlc }<7.0 \% \text { (NMA in Japanese } \\
\text { patients) }\end{array}$ & 100 & 132 & 100 & 135 \\
\hline
\end{tabular}

$H b A 1 c$ glycated hemoglobin, $N M A$ network meta-analysis, $S E$ standard error

(QALY) gained was calculated. This is due to the presentation of all cost of control endpoints in natural units (e.g., the cost of reducing HbA1c to $<7.0 \%$ in one patient) for which no willingness-to-pay thresholds are established. In increasing the transparency and simplicity of the analysis, this approach simultaneously limits the generalizability and comparability of the findings in the context of other economic analyses of anti-hyperglycemic agents. As with previous cost of control analyses, the present analysis is therefore intended to provide complementary information to assist decisionmakers with shorter time horizons [18].

When considering the importance of the findings, the clinical relevance of the pre-specified endpoints should first be considered. HbA1c targets of $\leq 6.5 \%$ and $<7.0 \%$ are considered clinically relevant by the American Association of Clinical Endocrinologists, the American Diabetes Association, and the JDS, who use the targets as the cornerstone of their respective treatment guidelines for T2D, [19] while bodyweight reductions of $5 \%$ or more have been shown to result in improvements in metabolic and cardiovascular risk factors [20].

The results of the present analysis are in agreement with similar analyses conducted for the US setting [14, 15]. These analyses found that once-weekly semaglutide $0.5 \mathrm{mg}$ was associated with a lower cost of control than dulaglutide $0.75 \mathrm{mg}$ for all endpoints included in the analyses. The analysis published in 2018 used the equivalent dataset to the present analysis, using observed data for all randomized patients exposed to at least one dose of trial product (full analysis set) obtained while on treatment and before onset of rescue medication [14]. The analysis published in 2019 used a slightly different dataset, based on the intentto-treat population in which missing data were imputed using multiple imputation based on retrieved dropout analysis [15]. That the findings did not differ when varying datasets were used supports the belief that the conclusions of the analysis are robust. A further cost of control analysis has been conducted in Spain, comparing once-weekly semaglutide with the higher 
dose of dulaglutide $1.5 \mathrm{mg}$ [16]. This analysis found that the cost of control was lower with once-weekly semaglutide $0.5 \mathrm{mg}$ than with dulaglutide $1.5 \mathrm{mg}$ for all endpoints included in the study. Given that dulaglutide $1.5 \mathrm{mg}$ is more efficacious than dulaglutide $0.75 \mathrm{mg}$, and that the two doses are associated with the same annual cost, once-weekly semaglutide $0.5 \mathrm{mg}$ can be presumed to have a lower cost of control than dulaglutide $0.75 \mathrm{mg}$ for all endpoints in Spain. The conclusion that semaglutide $0.5 \mathrm{mg}$ is associated with a lower cost of control than dulaglutide $0.75 \mathrm{mg}$ has been confirmed in the USA, Spain, and now Japan.

Given the lower HbA1c values achieved with once-weekly semaglutide $0.5 \mathrm{mg}$ compared with dulaglutide $0.75 \mathrm{mg}$, the analysis is likely to be highly conservative from the longer-term perspective of a decision-maker covering both the initial drug costs and subsequent treatment of diabetes complications; the short time horizon of the present analysis assumes that no significant differences in complication incidence would be observed, despite the superior reductions in HbA1c with semaglutide $0.5 \mathrm{mg}$ versus dulaglutide $0.75 \mathrm{mg}$. As with all modeling analyses, there are a number of caveats and limitations of the present study that should be acknowledged and considered when interpreting the results. Firstly, the captured costs and the payer perspective should be taken into account. The analysis included only drug costs; with costs of self-monitoring of blood glucose tests, costs of any interactions with healthcare professionals, or costs associated with onset or ongoing treatment of diabetes complications not captured. This approach was chosen to maintain the simplicity of the analysis, with the excluded aspects not expected to differ with semaglutide $0.5 \mathrm{mg}$ and dulaglutide $0.75 \mathrm{mg}$ over the short term. The use of wholesale acquisition costs for the drug costs may not be reflective of the costs ultimately borne by the healthcare payer due to privately negotiated discounts, manufacturer rebates, or patient copay to offset the cost of the drug. Work has recently been published on presenting budget impact calculations over ranges of discount or rebate scenarios for two comparators, which could be integrated into future cost of control analyses to present cost of control scenarios in which different discounts are secured for each comparator [21].

The SUSTAIN 7 RCT demonstrated that once-weekly semaglutide is superior to onceweekly dulaglutide in terms of reductions in HbA1c and bodyweight, both of which are clinically relevant endpoints in a population of patients with T2D, with an NMA in Japanese patients with T2D corroborating these results. The present cost of control analysis found that injectable once-weekly semaglutide $0.5 \mathrm{mg}$ was cost-saving compared with once-weekly dulaglutide $0.75 \mathrm{mg}$ in terms of bringing patients to any of the endpoints reported in the SUSTAIN 7 RCT in a Japanese setting. This finding was confirmed in Japanese patients with T2D based on an indirect network metaanalysis.

\section{ACKNOWLEDGEMENTS}

Funding. The study and the journal's Rapid Service and Open Access fees were supported by funding from Novo Nordisk Pharma Ltd.

Authorship. All named authors meet the International Committee of Medical Journal Editors (ICMJE) criteria for authorship for this article, take responsibility for the integrity of the work as a whole, and have given their approval for this version to be published.

Prior Presentation. A preliminary version of this cost of control analysis was presented at the 61st Annual Meeting of the Japan Diabetes Society, Tokyo, May 24-26, 2018.

Disclosures. Ataru Igarashi reports grants and other from Gilead Sciences KK., grants from Intuitive Surgical GK., grants from Boston Scientific Japan Inc., grants and personal fees from Pfizer Japan Inc., grants from Beckton Dickinson and Company, grants from Milliman Inc., personal fees and other from Terumo corporation, personal fees from Chugai Pharmaceuticals Inc., personal fees from Astellas Pharma Inc., other from Fuji film Inc., other from CSL 
Behring Japan Inc., personal fees from Sanofi Japan Inc., personal fees and other from Takeda Pharmaceutical Inc., personal fees from Nippon Boeringer Ingelheim Inc., personal fees from Ono pharmaceutical Inc., personal fees from Taiho pharmaceutical Co. Ltd., personal fees from Eisai Inc., personal fees from Abbvie GK, personal fees from Sumitomo Dainippon Pharma Inc., personal fees from Ayumi Pharmaceutical Inc., personal fees from Medilead Inc., personal fees from Novo Nordisk Japan Inc., personal fees from Novartis Pharma Inc., personal fees from GSK Inc., outside the submitted work.Barnaby Hunt and Richard Pollock are employees of Ossian Health Economics and Communications, which received consulting fees from Novo Nordisk Pharma Ltd. to support preparation of the analysis. Lars Wilkinson is an employee of and shareholder in Novo Nordisk A/S. Jakob Langer is an employee of Novo Nordisk Pharma Ltd.

Compliance with Ethics Guidelines. This article is based on previously conducted studies and does not contain any studies with human participants or animals performed by any of the authors.

Data Availability. All data generated or analyzed during this study are included in this published article/as supplementary information files.

Open Access. This article is licensed under a Creative Commons Attribution-NonCommercial 4.0 International License, which permits any non-commercial use, sharing, adaptation, distribution and reproduction in any medium or format, as long as you give appropriate credit to the original author(s) and the source, provide a link to the Creative Commons licence, and indicate if changes were made. The images or other third party material in this article are included in the article's Creative Commons licence, unless indicated otherwise in a credit line to the material. If material is not included in the article's Creative Commons licence and your intended use is not permitted by statutory regulation or exceeds the permitted use, you will need to obtain permission directly from the copyright holder. To view a copy of this licence, visit http://creativecommons.org/licenses/by$\mathrm{nc} / 4.0 /$.

\section{REFERENCES}

1. International Diabetes Federation. IDF Diabetes Atlas, 9th edition. Brussels, Belgium. 2019. Available from: https://www.diabetesatlas.org. Last accessed Feb 20, 2020.

2. Goto $A$, Noda $M$, Inoue $M$, Goto $M$, Charvat $H$. Increasing number of people with diabetes in Japan: Is this trend real? Intern Med. 2016;55(14):1827-30.

3. Tanaka S, Tanaka S, Iimuro S, Yamashita $H$, Katayama S, Akanuma Y, Yamada N, Araki A, Ito H, Sone H, Ohashi Y, Japan Diabetes Complications Study Group; Japanese Elderly Diabetes Intervention Trial Group. Predicting macro- and microvascular complications in type 2 diabetes: the Japan Diabetes Complications Study/the Japanese Elderly Diabetes Intervention Trial risk engine. Diabetes Care. 2013;36(5):1193-9.

4. Ohkubo Y, Kishikawa H, Araki E, et al. Intensive insulin therapy prevents the progression of diabetic microvascular complications in Japanese patients with non-insulin-dependent diabetes mellitus: a randomized prospective 6-year study. Diabetes Res Clin Pract. 1995;28:103-17.

5. Tominaga $\mathrm{M}$, Eguchi $\mathrm{H}$, Manaka $\mathrm{H}$, et al. Impaired glucose tolerance is a risk factor for cardiovascular disease, but not impaired fasting glucose: the Funagata Diabetes Study. Diabetes Care. 1999;22: 920-4.

6. The Japan Diabetes Society. Evidence-based Practice Guideline for the Treatment for Diabetes in Japan 2016. Tokyo, Japan. 2013. Available from: https:// www.jds.or.jp/modules/en/index.php?content_id= 44. Last accessed Dec 18, 2017.

7. Seino Y, Terauchi Y, Osonoi T, Yabe D, Abe N, Nishida T, Zacho J, Kaneko S. Safety and efficacy of semaglutide once weekly vs sitagliptin once daily, both as monotherapy in Japanese people with type 2 diabetes. Diabetes Obes Metab. 2018;20(2): 378-88.

8. Kaku K, Yamada Y, Watada H, Abiko A, Nishida T, Zacho J, Kiyosue A. Safety and efficacy of onceweekly semaglutide vs additional oral antidiabetic drugs in Japanese people with inadequately controlled type 2 diabetes: a randomized trial. Diabetes Obes Metab. 2018;20(5):1202-12. 
9. Shiroiwa T, Fukuda T, Ikeda S, Takura T, Moriwaki $\mathrm{K}$. Development of an official guideline for the economic evaluation of drugs/medical devices in Japan. Value Health. 2017;20(3):372-8.

10. Shiroiwa T, Fukuda T, Ikeda S, Takura T. New decision-making processes for the pricing of health technologies in Japan: the FY 2016/2017 pilot phase for the introduction of economic evaluations. Health Policy. 2017;121(8):836-41.

11. Kamae I, Thwaites R, Hamada A, Fernandez JL. Health technology assessment in Japan: a work in progress. J Med Econ. 2020;23(4):317-22.

12. Center for Outcomes Research and Economic Evaluation for Health, National Institute of Public Health $(\mathrm{C} 2 \mathrm{H})$. Guideline for preparing cost-effectiveness evaluation to the central social insurance medical council. Available from: https://c2h.niph. go.jp/tools/guideline/guideline_en.pdf. Last accessed Feb 20, 2020.

13. Pratley RE, Aroda VR, Lingvay I, Lüdemann J, Andreassen C, Navarria A, Viljoen A. SUSTAIN 7 investigators. Semaglutide versus dulaglutide once weekly in patients with type 2 diabetes (SUSTAIN 7): a randomised, open-label, phase $3 \mathrm{~b}$ trial. Lancet Diabetes Endocrinol. 2018;6(4):275-86.

14. Wilkinson L, Hunt B, Johansen P, Iyer NN, DangTan T, Pollock RF. Cost of achieving HbA1c treatment targets and weight loss responses with onceweekly semaglutide versus dulaglutide in the United States. Diabetes Ther. 2018;9(3):951-61.

15. Johansen P, Hunt B, Iyer NN, Dang-Tan T, Pollock RF. Cost of achieving HbA1c treatment targets and weight loss responses with once-weekly semaglutide versus dulaglutide in the United States. Diabetes Ther. 2018;9(3):951-61.
16. Vidal J, Malkin SJP, Hunt B, Martín V, Hallén N, Javier OF. The short-term cost-effectiveness of onceweekly semaglutide versus once-daily sitagliptin and once-weekly dulaglutide for the treatment of patients with type 2 diabetes: a cost of control analysis in Spain. Diabetes Ther. 2020;11(2): 509-21.

17. Webb N, Orme M, Witkowski M, Nakanishi R, Langer J. A network meta-analysis comparing semaglutide once-weekly with other GLP-1 receptor agonists in Japanese patients with type 2 diabetes. Diabetes Ther. 2018;9(3):973-86.

18. Hunt B, Mocarski M, Valentine WJ, Langer J. Evaluation of the short-term cost-effectiveness of IDegLira versus continued up-titration of insulin Glargine U100 in patients with type 2 diabetes in the USA. Adv Ther. 2017;34(4):954-65.

19. Garber AJ, Abrahamson MJ, Barzilay JI, et al. Consensus statement by the American association of clinical endocrinologists and American college of endocrinology on the comprehensive type 2 diabetes management algorithm-2017 executive summary. Endocr Pract. 2017;23(2):207-38.

20. Douketis JD, Macie C, Thabane L, Williamson DF. Systematic review of long-term weight loss studies in obese adults: clinical significance and applicability to clinical practice. Int $\mathrm{J}$ Obes (Lond). 2005;29(10):1153-67.

21. Lane WS, Weatherall J, Gundgaard J, Pollock RF. Insulin degludec versus insulin glargine U100 for patients with type 1 or type 2 diabetes in the US: a budget impact analysis with rebate tables. J Med Econ. 2018;21(2):144-51. 